\title{
Treatment decision satisfaction and regret after focal HIFU for localized prostate cancer
}

\author{
Niklas Westhoff ${ }^{1}\left(\mathbb{D} \cdot\right.$ Ramona Ernst $^{1} \cdot$ Karl Friedrich Kowalewski $^{1}$ (D) $\cdot$ Laura Schmidt $^{2} \cdot$ Thomas Stefan Worst $^{1}$ (1) . \\ Maurice Stephan Michel $^{1}$. Jost von Hardenberg ${ }^{1}$
}

Received: 29 April 2020 / Accepted: 3 June 2020 / Published online: 12 June 2020

(c) The Author(s) 2020

\begin{abstract}
Purpose Focal therapies (FTs) are investigated within prospective studies on selected patients treated for localized prostate cancer $(\mathrm{PCa})$. Benefits are preservation of genitourinary function and reduced complications, but follow-up is elaborate and is associated with uncertainty as cancer-free survival appears to be lower compared to standard radical treatments. The aim of this study was to analyse patient-reported acceptance of FT and evaluate factors associated with treatment decision regret. Methods 52 patients who received focal high-intensity focused ultrasound for low- to intermediate-risk PCa between 2014 and 2019 within two prospective trials were eligible for a survey regarding PCa-related treatment regret and quality-of-life (Clark's scale) and the following potential predictors: sociodemographic variables, Charlson Comorbidity Index, subjective aging (AARC-10 SF), and general health-related quality-of-life (SF-12). Cancer persistence/recurrence (multiparametric MRI and fusion biopsy after 12 months) and functional outcomes (EPIC-26 UI/UIO/S) data were also included in this study. Results The overall survey response rate was $92.3 \%$ (48/52 patients). Median follow-up was 38 months (interquartile range $=25-50$ months). In total, ten patients (20.8\%) reported treatment decision regret. In univariable analyses, a clinically meaningful increase in urinary incontinence showed a significant association (OR 4.43; 95\% CI 0.99-20.53; $p=0.049)$ with regret. Cancer recurrence (OR 12.31; 95\% CI 1.78-159.26; $p=0.023$ ) and general health worry as a domain of Clark's scale (OR 1.07; 95\% CI 1.03-1.14; $p<0.01$ ) were predictors of regret in a multivariable logistic regression model (AUC $=0.892$ ). Conclusion Acceptance of FT is comparable to standard treatments. Extensive follow-up including regular PSA testing does not cause additional regret but careful patient selection and information before FT is crucial.
\end{abstract}

Keywords Focal therapy $\cdot$ High-intensity focused ultrasound $\cdot$ Prostate neoplasms $\cdot$ Recurrence $\cdot$ Regret

\section{Introduction}

Prostate cancer $(\mathrm{PCa})$ is the second most frequent cancer in men and the fifth leading cause of death from cancer worldwide [1]. In patients with a life expectancy of more than

Electronic supplementary material The online version of this article (https://doi.org/10.1007/s00345-020-03301-0) contains supplementary material, which is available to authorized users.

Niklas Westhoff

niklas.westhoff@medma.uni-heidelberg.de

1 Department of Urology and Urosurgery, Medical Faculty Mannheim, Heidelberg University, Theodor-Kutzer-Ufer 1-3, 68167 Mannheim, Germany

2 Department of Health Psychology, Institute of Psychology, Heidelberg University, Hauptstraße 47-51, 69117 Heidelberg, Germany
10 years, cancers at a low risk for progression and metastasis can be monitored with Active Surveillance (AS) protocols to spare or postpone radical treatment. If a clinically significant localized PCa is present or if patients ask for active treatment, curative treatment options comprise surgery [robotic assisted or open radical prostatectomy (RP)] and radiation therapy (external beam radiation therapy (EBRT) and/or brachytherapy (BT)) [2].

A patient's decision for a particular therapy option in localized PCa is mainly based on the spectrum of sideeffects since PCa-specific mortality is low irrespective of the kind of treatment [3]. Side-effects after radiation therapy include voiding symptoms, bowel dysfunction, sexual dysfunction, and secondary malignancies. After RP, urinary incontinence and sexual dysfunction are the most relevant side-effects $[3,4]$. Focal therapy (FT) has been developed to reduce the side-effects of whole-gland treatments, to 
maintain genitourinary function, and to provide equivalent oncologically safe treatment. Ablative approaches such as high-intensity focused ultrasound (HIFU), irreversible electroporation, and focal BT treat intraprostatic cancer lesions locally while sparing benign organ tissue [5]. Although the overall quality of evidence of the oncological effectiveness compared to standard treatments is still low and there is a lack of long-term follow-up, recent data show a favourable toxicity profile for FT [5].

Decision-making is a sophisticated process for patients: an unfavourable outcome, either regarding the oncological prognosis or quality-of-life, can lead to regret over the treatment selected, the choice itself, or the outcome [6]. During recent years, measurement of regret after PCa treatment has become an emerging instrument to define factors associated with acceptance of therapy choice [7-10].

To implement FTs into the algorithm of PCa treatment, it is first necessary to characterize how patients evaluate their decision for and experience with this treatment. However, no data exists on the postoperative acceptance of FT, patients' well-being, and self-reported treatment outcomes. Thus, the aim of this prospective cohort study was to determine regret of FT and to identify potentially associated oncologic, sociodemographic, functional, age-related, and quality-of-life factors as well as the influence of informed decision-making.

\section{Subjects and methods}

\section{Patients}

Between October 2014 and July 2019, 61 patients were treated by HIFU within the registered prospective singlecenter trials FOXPRO and FOXPRO-REGISTER (at germanctr.de; DRKS00007105 and DRKS00009021). The studies were approved by the institutional ethical review committee (No. 2014-423 M-MA and 2015-401 M-MA). All patients gave written informed consent. Inclusion criteria were a low-to-intermediate-risk PCa and a PI-RADS 3-5 target lesion as determined by multiparametric magnetic resonance imaging (mpMRI) of the prostate. If the mpMRI was negative, a biopsy-proven cancer limited to one prostate zone was accepted. The technique of HIFU and the study workflow were described in detail previously [11].

\section{Data acquisition and survey questionnaire}

By study protocol, oncological treatment outcomes and patient-reported functional outcomes were recorded at 3, 6, 12, 24, and 36 months. Oncological follow-up included repeated measurements of prostate-specific antigen (PSA) levels. At 12 months, or before in cases of rising PSA, patients received a control mpMRI and an MRI/ ultrasound-fusion prostate biopsy to assess recurrence or persistence of cancer. The genitourinary functional outcome was measured by validated questionnaires by comparing values before HIFU treatment (baseline) and at follow-up. We used the well-established Expanded Prostate Cancer Index Composite 26 (EPIC-26) questionnaire set, which is a patient-reported outcome questionnaire to monitor healthrelated quality-of-life outcomes among patients after $\mathrm{PCa}$ therapy. The three domains for urinary incontinence (EPIC26 UI), irritative/obstructive symptoms (EPIC-26 UIO), and sexuality (EPIC-26 S) were selected (Online Resource 1). The summary scores for the domains ranged from 0 to 100 with lower values representing worsening genitourinary function [12]. Established Minimal Important Differences (MIDs) were used to determine the number of patients who reported a clinically meaningful change of outcome during follow-up [13].

The survey data for regret of therapy were collected between September and October of 2019. Patients received a questionnaire that was subdivided into different parts. Part one requested sociodemographic parameters, which were patient age, marital status, housing situation, education, employment status, and health insurance. Part two consisted of questions regarding chronic and oncological diseases for calculation of the Charlson Comorbidity Index. This score weights existing comorbidities to predict a 10 -year survival probability [14]. For part three, Clark's validated scale was used to assess PCa-related quality-of-life. Nineteen statements are allocated to the 5 domains "treatment decision regret" (five statements), "having made an informed decision" (four statements), "health worry" (six statements), "PSA concern" (two statements), and "outlook" (two statements). Ratings of how true the statements were perceived ranged from 1 (not at all) to 5 (very much) and scales were scored afterwards from 0 to 100 according to Clark's recommended scoring procedure. A score of $\geq 40$ was classified as a treatment decision regret [9] (Online Resource 2). In part four of the survey, patients' self-perceptions of aging were assessed using the Awareness of Age-Related Change Short Form (AARC-10 SF). The short form was developed in 2017 from the 50 item AARC and contains five statements that describe gains of aging and five statements that describe losses (e.g.,"With my increasing age, I realize that ... I have a better sense of what is important to me" or "... I feel more dependent on the help of others"). Ratings of the statements ranged from 1 (not at all) to 5 (very much) and were summed up as two separate scores where higher values indicate higher levels of perceived gains or losses. In addition, we assessed the "subjective" or "felt" age ("Many people feel older or younger than they actually are. Fill in the age (in years) that you feel most of the time:...") [15]. Following the recommendation of Rubin and Berntsen, we calculated the proportional discrepancy (discrepancy between 
felt and chronological age divided by chronological age) [16]. Part five was the Short Form Health Survey (SF-12), a shortened version of the SF-36, which is frequently used to collect data on general health-related quality-of-life [17]. A general health rating was assessed by one introductory question which was subsequently used for further association analyses.

\section{Statistical analyses}

Categorical data are provided as absolute and relative frequencies. Location parameters of continuous data are reported as median or mean. Measures of variation are reported as range, interquartile range (IQR), or standard deviation (SD). For sociodemographic, histopathological, functional, quality-of-life, and age-related variables, the association with regret of FT was evaluated by univariable analyses. Factors that predict regret of FT were defined by a multivariable logistic regression model which included statistically significant variables of univariable analyses. Receiver operating characteristic (ROC) curves were generated for the independent predictors of regret. Statistical significance was set at $p$ values $<0.05$. Statistical analyses were performed using $\mathrm{R}$ version 3.5.2 ( $\mathrm{R}$ project, $\mathrm{R}$ Foundation for Statistical Computing) and $\mathrm{JMP}^{\circledR}$ (version 14.0.0, SAS Institute Inc., USA).

\section{Results}

Of the 61 patients who received HIFU therapy, 52 patients were eligible for the survey. Reasons for exclusion were: seven patients discontinued study follow-up; 1 patient had developed dementia; and 1 patient died (a non-PCa-related event). A total of 48 patients completed questionnaires, corresponding to a survey response rate of $92.3 \%$. All the four patients who did not respond showed residual or recurrent cancer in the control biopsy after HIFU treatment. The mean patient age was 68.0 years (SD 7.9 years) at HIFU therapy and 71.0 years (SD 8.2 years) at survey. Whereas the median follow-up time (from HIFU to survey completion) was 38 months (range of 25-50 months), in five patients (10.4\%), the interval was less than 12 months. These patients had not yet received the control mpMRI and biopsy. The sociodemographic baseline characteristics of the cohort are shown in Table 1. Most patients were married, living with a partner or flatmate, and in retirement.

Results of the control biopsy were available for $70.8 \%$ of the patients. Beside the five patients (10.4\%) with an outstanding MRI and biopsy, nine patients (18.8\%) rejected the biopsy due to decreasing PSA levels or unsuspicious mpMRI. Cancer was found in the control biopsies of 22 patients (45.8\%), of whom 12 patients (25\%) had a Gleason
Table 1 Sociodemographic characteristics

\begin{tabular}{|c|c|}
\hline Parameter & Value \\
\hline $\begin{array}{l}\text { Number of patients with completed regret of therapy } \\
\text { follow-up }\end{array}$ & 48 \\
\hline \multicolumn{2}{|l|}{ Mean patient age, years (SD) } \\
\hline At HIFU & $68.0(7.9)$ \\
\hline At survey & $71.0(8.2)$ \\
\hline Median time from HIFU to survey, months (IQR) & $38(25-50)$ \\
\hline Time from HIFU to survey $<12$ months $(n, \%)$ & $5(10.4)$ \\
\hline \multicolumn{2}{|l|}{ Marital status $(n, \%)$} \\
\hline Yes & $40(83.3)$ \\
\hline No & $5(10.4)$ \\
\hline $\mathrm{n} / \mathrm{a}$ & $3(6.3)$ \\
\hline \multicolumn{2}{|l|}{ Housing situation $(n, \%)$} \\
\hline With partner/shared flat & $41(85.4)$ \\
\hline Alone & $4(8.3)$ \\
\hline $\mathrm{n} / \mathrm{a}$ & $3(6.3)$ \\
\hline \multicolumn{2}{|l|}{ Educational qualification $(n, \%)$} \\
\hline University/college & $26(54.2)$ \\
\hline Lower & $21(43.8)$ \\
\hline $\mathrm{n} / \mathrm{a}$ & $1(2.1)$ \\
\hline \multicolumn{2}{|l|}{ Employment status $(n, \%)$} \\
\hline Full- or part-time & $10(20.8)$ \\
\hline Retired & $37(77.1)$ \\
\hline $\mathrm{n} / \mathrm{a}$ & $1(4.3)$ \\
\hline \multicolumn{2}{|l|}{ Insurance $(n, \%)$} \\
\hline Private & $18(37.5)$ \\
\hline Statutory or combined private & $28(58.4)$ \\
\hline $\mathrm{n} / \mathrm{a}$ & $2(4.2)$ \\
\hline
\end{tabular}

$H I F U$ high-intensity focused ultrasound, $n / a$ not applicable

Score of $\geq 3+4$ (clinically significant cancer). One-third of patients $(n=16)$ received a salvage therapy by radical prostatectomy $(n=7)$, EBRT $(n=6)$, re-HIFU $(n=2)$, or androgen deprivation therapy $(n=1)$. A clinically meaningful impairment of urinary continence was recorded in 12 patients (25\%), of irritative and obstructive symptoms in 11 patients (22.9\%), and of erectile function in 14 patients (29.2\%) (Table 2).

Most men reported being in good-to-excellent general health $(85.4 \%)$ (SF-12). Of five patients who reported poor or very poor health, three received salvage therapy due to cancer detection in the control biopsy. Patients usually felt younger than their chronological age, which resulted in a mean discrepancy of -10.4 years (SD 9.8 years) (AARC$10 \mathrm{SF}$ ). This corresponded to a proportional discrepancy score of -0.14 (SD 0.12). There was a higher likelihood to perceive gains rather than losses in terms of the variance of patients' age-related self-perceptions (mean score 16.7 vs. 11.0) (Table 3). 
Table 2 Comparison of oncological and functional outcomes prior to high-intensity focused ultrasound (HIFU) and at time of follow-up 12 months after HIFU

\begin{tabular}{|c|c|c|}
\hline Parameter & At baseline (prior to HIFU) & At follow-up (after HIFU) \\
\hline \multicolumn{3}{|l|}{ Prostate biopsy $(n, \%)$} \\
\hline Completed & $48(100)$ & $34(70.8)$ \\
\hline Rejected by patient & & $9(18.8)$ \\
\hline Outstanding & & $5(10.4)$ \\
\hline \multicolumn{3}{|l|}{ PSA, ng/ml } \\
\hline Increase $(n, \%)$ & & $16(33.3)$ \\
\hline No increase $(n, \%)$ & & $32(66.6)$ \\
\hline \multicolumn{3}{|l|}{ Gleason score at biopsy $(n, \%)$} \\
\hline $3+3$ & $26(54.2)$ & $10(20.8)$ \\
\hline $3+4$ & $17(35.4)$ & $8(16.7)$ \\
\hline$\geq 4+3$ & $5(10.4)$ & $4(8.3)$ \\
\hline \multicolumn{3}{|l|}{ Salvage therapy $(n, \%)$} \\
\hline Yes & & $16(33.3)$ \\
\hline No & & $32(66.6)$ \\
\hline \multicolumn{3}{|l|}{ Voiding function } \\
\hline \multicolumn{3}{|l|}{ EPIC-26 Urinary Incontinence domain } \\
\hline Mean (range) & $95.6(66.8-100)$ & $89.2(46-100)$ \\
\hline Clinically meaningful impairment $(n, \%)^{\mathrm{a}}$ & & $12(25)$ \\
\hline $\mathrm{n} / \mathrm{a}$ & & $10(20.8)$ \\
\hline \multicolumn{3}{|l|}{ EPIC-26 Urinary irritative/obstructive domain } \\
\hline Mean (range) & $90.1(37.5-100)$ & $90.3(56.3-100)$ \\
\hline Clinically meaningful impairment $(n, \%)^{\mathrm{b}}$ & & $11(22.9)$ \\
\hline $\mathrm{n} / \mathrm{a}$ & & $11(22.9)$ \\
\hline \multicolumn{3}{|l|}{ Erectile function } \\
\hline \multicolumn{3}{|l|}{ EPIC-26 Sexual domain } \\
\hline Mean (range) & $68.3(0-100)$ & $58.2(8.3-100)$ \\
\hline Clinically meaningful impairment $(n, \%)^{\mathrm{c}}$ & & $14(29.2)$ \\
\hline $\mathrm{n} / \mathrm{a}$ & & $10(20.8)$ \\
\hline
\end{tabular}

$H I F U$ high-intensity focused ultrasound, EPIC-26 expanded prostate cancer index composite 26, n/a not applicable

${ }^{a}$ Minimal important difference (MID): a decrease of $\geq 6$ points from baseline to latest available follow-up

${ }^{\mathrm{b}} \mathrm{MID}$ of $\geq 5$ points

${ }^{\mathrm{c}} \mathrm{MID}$ of $\geq 10$ points
According to Clark's PCa-related quality-of-life assessment, ten patients (20.8\%) described treatment decision regret. Comparing patients with regret to those without, $80 \%$ vs. $36.8 \%$ ( $p=0.025$ ), respectively, had cancer at control biopsy. More patients reported a clinically meaningful worsening of incontinence (50\% vs. $18.4 \%$; $p=0.049)$ and levels of health worry were higher (41.67 vs. $25.0 ; p=0.003)$. Table 4 demonstrates the results of uni- and multivariable analyses of factors associated with regret of therapy. In the multivariable logistic regression model, cancer at control biopsy and general health worry were predictors of treatment decision regret $(p=0.025$ and $p=0.009$, respectively). Combining both variables results in an AUC of 0.892 (Online Resource 3).

\section{Discussion}

Treatment decision in localized PCa challenges patients and is, besides the goal of curing cancer, mainly based on therapy-related side-effects and patients' preferences $[18,19]$. Consequently, patient-reported outcomes should be gathered and presented in a comprehensible manner. Patients can better choose a treatment by assessing 
Table 3 General health status, comorbidity, awareness of age-related change and prostate cancer-related quality-of-life of patients at follow-up after high-intensity focused ultrasound (HIFU)

\begin{tabular}{|c|c|}
\hline Parameter & Value \\
\hline \multicolumn{2}{|l|}{ SF-12 health-related QoL } \\
\hline \multicolumn{2}{|l|}{ General health rating } \\
\hline Excellent/very good, $(n, \%)$ & $13(27.1)$ \\
\hline $\operatorname{Good}(n, \%)$ & $28(58.3)$ \\
\hline Poor/very poor $(n, \%)$ & $5(10.4)$ \\
\hline Physical component score (mean, SD) & $48.3(6.9)$ \\
\hline Mental component score (mean, SD) & $53.1(7.3)$ \\
\hline $\begin{array}{l}\text { No. of patients with physical component score }>50 \\
(\%)\end{array}$ & $22(45.8)$ \\
\hline $\begin{array}{l}\text { No. of patients with mental component score }>50 \\
(\%)\end{array}$ & $36(75)$ \\
\hline Item missing $(n, \%)$ & $2(4.2)$ \\
\hline Charlson Comorbidity Index, \% (mean, SD) & $29.8(25.3)$ \\
\hline \multicolumn{2}{|l|}{ Measures of subjective age (mean, SD) } \\
\hline AARC-10 SF gains ${ }^{\mathrm{a}}$ & $16.7(3.3)$ \\
\hline AARC-10 SF losses ${ }^{a}$ & $11.0(3.3)$ \\
\hline Discrepancy of felt and chronological age in years & $-10.4(9.8)$ \\
\hline Proportional discrepancy score ${ }^{b}$ & $-0.14(0.12)$ \\
\hline Item missing $(n, \%)$ & $3(6.3)$ \\
\hline \multicolumn{2}{|l|}{ Clark's prostate cancer-related QoL } \\
\hline Health worry $(\text { mean, } S D)^{c}$ & $42.3(22.6)$ \\
\hline PSA concern $(\text { mean, } S D)^{d}$ & $88.0(15.1)$ \\
\hline Outlook (mean, SD) ${ }^{\mathrm{e}}$ & $51.6(23.2)$ \\
\hline Informed decision index $(\text { mean, } S D)^{\mathrm{f}}$ & $88.7(17.1)$ \\
\hline Treatment regret index $\geq 40(n, \%)^{\mathrm{g}}$ & $10(20.8)$ \\
\hline Item missing $(n, \%)$ & $1(2.1)$ \\
\hline
\end{tabular}

$A A R C$-10 SF awareness of age-related change short form, HIFU highintensity focused ultrasound, $S F-12$ short form health survey, $Q o L$ quality of life

${ }^{\text {a } H i g h e r ~ v a l u e s ~ i n d i c a t e ~ h i g h e r ~ l e v e l s ~ o f ~ p e r c e i v e d ~ g a i n s ~ o r ~ l o s s e s ~}$

${ }^{\mathrm{b}}$ Higher values indicate less discrepancy of felt and chronological age

${ }^{c}$ Higher values indicate greater worry

${ }^{\mathrm{d}}$ Higher values indicate greater concern

${ }^{\mathrm{e}}$ Higher values indicate better outlook

${ }^{\mathrm{f}}$ Higher values indicate more informed decision

${ }^{g}$ Values $\geq 40$ indicate regret

potential physical functional outcomes like sexual dysfunction and incontinence, and perceived psychosocial consequences such as loss of libido and depression. Therefore, measuring treatment decision regret is of increasing interest in localized PCa, because it quantifies how patients rate their treatment $[7,9]$. A growing body of knowledge in this field can guide urologists to improve patient information and shared decision-making.

In this analysis of patients treated by focal HIFU, 20.8\% of patients (10/48) reported treatment decision regret. It is relevant to note, that these results are generated from study patients. Since focal PCa therapies are not standardised and different approaches and technologies exist, it is critical to perform prospective trials when evaluating them [20]. These study protocols include follow-ups to measure PSA at defined intervals and another mpMRI and prostate biopsy for control after treatment. In cases of cancer persistence or recurrence, salvage therapies might be considered. Some low-risk cancers may undergo AS. In addition, adverse events, functional status, and quality-of-life should be measured during follow-up [20]. Although undoubtedly indicated, these frequent follow-up visits can lead to distress and anxiety and consequently increase the perception of decision regret.

The extent of decision regret for FT is comparable with regret after standard treatments of localized PCa. In a recent prospective multicenter study, $23 \%$ of patients reported a clinically relevant treatment regret after 12 months, irrespective of the kind of treatment. Extent of regret was 37\% after EBRT, 23\% after RP, $20 \%$ after AS, and $18 \%$ after BT, but there was no statistical significant difference $(p>0.05)$ [21]. Hoffman et al. evaluated regret among long-term survivors 15 years after local therapy $(n=934)$. The overall regret rate was $14.6 \%$, with $16.6 \%$ expressing regret after EBRT/ BT, $15 \%$ after RP, and $8.2 \%$ after conservative management [8]. In a systematic review of 28 articles, regret rates varied between 0.5 and $31 \%$ for RP, 9.2-24\% for EBRT, and 0-24\% for BT [7]. Although FTs are new and knowledge of potential complications, early and late side-effects, and oncological outcomes are still very limited, patients who received FT did not express more regret about their treatment decision compared to patients who chose a radical treatment. At the same time, a potential preservation of genitourinary function did not improve regret rates in favour of FT. Notably, within these studies, regret was also measured by instruments other than the Clark's scale (e.g., Decision Regret Scale [22]), thereby reducing comparability. Moreover, there are no scales that classify whether patients feel lower or higher levels of regret making it difficult to compare the extent of regret between different cohorts.

Two situations are responsible for development of regret after treatment when there is no definitive preferable clinical therapy (i.e., a "preference-sensitive" cancerrelated decision): either a lack of positive outcomes or occurrence of worse outcomes [8]. In our analyses, cancer persistence/recurrence at control biopsy was strongly correlated with treatment decision regret. Thus, these patients experienced a lack of an expected positive oncological outcome. As part of our study protocol and according to recommendations, we performed a detailed therapy control by mpMRI and a targeted biopsy of the treated and a systematic biopsy of the untreated prostate tissue. The overall cancer recurrence rate in this study was $45.8 \%$, including clinically significant and insignificant cancers. 
Table 4 Logistic regression model of factors associated with regret of focal therapy

\begin{tabular}{|c|c|c|c|c|c|c|c|}
\hline \multirow[t]{2}{*}{ Variable } & \multirow[t]{2}{*}{ Direction and unit } & \multicolumn{3}{|c|}{ Univariable analyses } & \multicolumn{3}{|c|}{ Multivariable analyses } \\
\hline & & Odds Ratio & $95 \% \mathrm{CI}$ & $p$ value & Odds Ratio & $95 \% \mathrm{CI}$ & $p$ value \\
\hline Age $\geq 65$ years & Yes vs. no & 1.89 & $0.45-9.80$ & 0.4047 & & & \\
\hline Married & Yes vs. no & 1.00 & $0.12-20.99$ & 1.0000 & & & \\
\hline Housing situation & $\begin{array}{l}\text { Living with partner or shared flat } \\
\text { (vs. living alone) }\end{array}$ & 0.73 & $0.08-15.78$ & 0.7941 & & & \\
\hline Education & University or college (vs. lower) & 0.58 & $0.13-2.53$ & 0.4684 & & & \\
\hline Employment & Full-/part time (vs. retired) & 0.40 & $0.02-2.66$ & 0.4198 & & & \\
\hline Insurance & Private/combined (vs. statutory) & 0.53 & $0.10-2.32$ & 0.4125 & & & \\
\hline PSA increase & Yes vs. no & 1.44 & $0.32-6.05$ & 0.6163 & & & \\
\hline Cancer recurrence & Yes vs. no & 6.86 & $1.47-49.89$ & 0.0250 & 12.31 & $1.78-159.26$ & 0.0225 \\
\hline Recurrent Gleason Score $3+3$ & Yes vs. no & 1.33 & $0.23-7.97$ & 0.7464 & & & \\
\hline Recurrent Gleason Score $\geq 3+4$ & Yes vs. no & 0.75 & $0.13-4.40$ & 0.7464 & & & \\
\hline Salvage therapy & Yes vs. no & 2.45 & $0.58-10.57$ & 0.2165 & & & \\
\hline Urinary incontinence & CMI vs. no CMI & 4.43 & $0.99-20.53$ & 0.0497 & 5.67 & $0.76-56.97$ & 0.1010 \\
\hline $\begin{array}{l}\text { Urinary irritative/obstructive } \\
\text { symptoms }\end{array}$ & CMI vs. no CMI & 1.61 & $0.30-7.37$ & 0.5514 & & & \\
\hline Erectile dysfunction & CMI vs. no CMI & 0.54 & $0.07-2.58$ & 0.4780 & & & \\
\hline General health rating & $\begin{array}{l}\text { Excellent/very good/good (vs. } \\
\text { poor/very poor) }\end{array}$ & 0.26 & $0.05-3.10$ & 0.3090 & & & \\
\hline Charlson Comorbidity Index & Increasing units & 0.11 & $0.003-2.13$ & 0.1783 & & & \\
\hline $\begin{array}{l}\text { Proportional age discrepancy } \\
\text { score }\end{array}$ & Increasing units & 5.55 & $0.01-5922.09$ & 0.5997 & & & \\
\hline AARC-10 gains & Increasing units & 1.01 & $0.82-1.27$ & 0.8968 & & & \\
\hline AARC-10 losses & Increasing units & 0.99 & $0.79-1.22$ & 0.8961 & & & \\
\hline Health worry & Increasing units & 1.06 & $1.03-1.12$ & 0.0034 & 1.07 & $1.03-1.14$ & 0.0096 \\
\hline PSA concern & Increasing units & 1.02 & $0.97-1.09$ & 0.4521 & & & \\
\hline Outlook & Increasing units & 0.99 & $0.96-1.02$ & 0.5354 & & & \\
\hline Informed decision making & Increasing units & 0.96 & $0.91-1.00$ & 0.0987 & & & \\
\hline
\end{tabular}

Bold values are indicate statistically significant variables

Urinary incontinence, urinary irritative/obstructive symptoms, erectile dysfunction: domains of EPIC-26; General health rating: Item of SF-12; Health worry, PSA concern, Outlook, Informed decision making: domains of Clark's scale

$A A R C-10$ awareness of age-related change short form, $C I$ confidence interval, $C M I$ clinically meaningful impairment, $P S A$ prostate specific antigen

Recent FT trial data show similar rates of treatment failures among different modalities [23, 24]. Major reasons for these high rates are the multifocality of $\mathrm{PCa}$, imaging and biopsy errors, and inappropriate patient selection [25]. Consequently, patients should be well informed about the risk of relapse to reduce regret after treatment. Only those patients who accept potential further salvage treatments should be admitted to FT. These patients should also be informed that the evidence of outcome from salvage treatments is very low but that preliminary data indicate slightly worse oncological and functional outcomes [26]. Interestingly, patients with a low-risk PCa at control biopsy, defined by a Gleason Score of $3+3$, were more likely to express regret than patients with clinically significant cancers. In addition, receiving a salvage therapy showed no correlation in this series. One explanation may be that patients who received salvage therapies were satisfied with its course and outcome. Patients with low-risk cancers frequently (60\%) underwent AS which could have caused emotional distress and a feeling of loss of control over their cancer, or otherwise led to decreased satisfaction when AS had already been a primary option before choice of FT.

Regarding functional outcomes, $25 \%$ of patients reported a clinically meaningful impairment of urinary continence at their last follow-up which was associated with regret in univariable analyses but not in the multivariable model. Urinary irritative/obstructive symptoms and erectile dysfunction did not predict regret. A significant correlation with urinary incontinence was also reported in a comprehensive review by Christie et al. [7]. Although urinary incontinence is more frequent after RP and EBRT, it can increase after FT 
and especially for apical cancers. If patients were previously unprepared, unexpected urinary incontinence could cause a higher level of disappointment [27, 28].

A greater general health worry was another significant predictor of decision regret. It is reasonable that patients who are highly concerned about their health status, results of medical examinations, or disease-related death are sensitive to worse outcomes [9]. These patients should be identified before decision-making, for example by questionnaires, to optimally provide informational content.

The role of PSA testing for follow-up after treatment is under debate since there is no nadir due to tissue preservation. This may cause uncertainty for patients. However, a PSA increase or general PSA concern did not affect acceptance of FT. Moreover, in this cohort, social circumstances (marital and housing situation, employment and insurance status) and educational level did not influence occurrence of regret. In contrast, van Stam et al. showed a correlation with educational level in standard treatments [21]. Although patients of higher age ( $\geq 65$ years) were more likely to express regret and patients generally felt younger than their true age, there was no significant correlation between regret and age itself, felt age discrepancy, and perceived agerelated gains or losses.

Our study has some limitations. First, our sample size was small which limits statistical significance. However, our sample size was similar to other prospective studies of FT and is explained by its novelty and highly selected patient population. Second, it is questionable whether these results after focal HIFU therapy can be transferred to other FT modalities. Different recurrence rates and side-effects might affect regret rates. Nevertheless, HIFU is one of the most common FTs and, therefore, more data for this treatment alternative are highly needed. Third, the time interval between FT and assessment of regret varied between the patients and was longer for those reporting regret. Reports from long-term follow-up after standard treatments also showed that regret increased over time [8]. Last, we cannot make a direct comparison to standard treatment options. Instruments that measure regret vary, but the Clark's scale that was used in this study is one of the two most common tools.

In conclusion, in localized $\mathrm{PCa}$ "preference-sensible" treatment decisions are common. Analysing regret of treatment decisions is a helpful instrument to measure acceptance after FT. This first prospective cohort study of patients treated by FT showed that overall treatment acceptance was comparable to standard treatments. Cancer recurrence, functional outcomes and a general health worry can lead to treatment decision regret but follow-up by regular PSA testing with its particular uncertainty in interpretation after FT does not. Future studies might address moderating variables related to health worry with the potential to explain variance in decision regret or explore therapy-related expectations within larger patient populations. This will pave the way for comparative studies analysing regret of FT versus standard treatment options. To circumvent treatment decision regret, awareness of current cancer persistence/recurrence rates and side-effects will allow urologists to provide comprehensive information and further improve careful patient selection and shared decision-making.

Acknowledgements Open Access funding provided by Projekt DEAL. This work is supported by the H.W. and J. Hector Foundation, Weinheim, Germany. We would like to acknowledge our study nurse Simone Zendler for supporting the course of the study.

Author's contributions NW: project development, data collection, data analysis, manuscript writing. RE: data collection, manuscript editing. KFK: data analysis, manuscript editing. LS: project development, manuscript editing. TSW: manuscript editing. MSM: manuscript editing. $\mathrm{JvH}$ : project development, data collection, data analysis, manuscript editing.

Funding This work is supported by the H.W. and J. Hector Foundation, Weinheim, Germany.

Data availability The data that support the findings of this study are available from the corresponding author upon reasonable request.

\section{Compliance with ethical standards}

Conflict of interest Karl-Friedrich Kowalewski received travel and non-financial support from Intuitive Surgical and CMR Surgical. All other authors declare no conflict of interest.

Human participants and/or animals This study was performed in line with the principles of the Declaration of Helsinki. Approval was granted by the institutional ethical review committee (No. 2014423 M-MA and 2015-401 M-MA).

Informed consent Informed consent was obtained from all individual participants included in the study.

Open Access This article is licensed under a Creative Commons Attribution 4.0 International License, which permits use, sharing, adaptation, distribution and reproduction in any medium or format, as long as you give appropriate credit to the original author(s) and the source, provide a link to the Creative Commons licence, and indicate if changes were made. The images or other third party material in this article are included in the article's Creative Commons licence, unless indicated otherwise in a credit line to the material. If material is not included in the article's Creative Commons licence and your intended use is not permitted by statutory regulation or exceeds the permitted use, you will need to obtain permission directly from the copyright holder. To view a copy of this licence, visit http://creativecommons.org/licenses/by/4.0/.

\section{References}

1. Rawla P (2019) Epidemiology of prostate cancer. World J Oncol 10(2):63-89. https://doi.org/10.14740/wjon1191 
2. Mottet $\mathrm{N}$ van den Bergh RCN Briers E De Santis M Fanti S Gillessen S Grummet J Henry AM Lam TB Mason MD van der Kwast TH van der Poel HG Rouvière O Schoots IG Tilki D Wiegel T (2019) EAU-EANM-ESTRO-ESUR-SIOG guidelines on prostate cancer. European association of urology. Arnhem, The Netherlands. https://uroweb.org/guideline/prostate-cancer/. Accessed 17 Mar 2020

3. Hamdy FC, Donovan JL, Lane JA, Mason M, Metcalfe C, Holding P, Davis M, Peters TJ, Turner EL, Martin RM, Oxley J, Robinson M, Staffurth J, Walsh E, Bollina P, Catto J, Doble A, Doherty A, Gillatt D, Kockelbergh R, Kynaston H, Paul A, Powell P, Prescott S, Rosario DJ, Rowe E, Neal DE, Protec TSG (2016) 10-Year outcomes after monitoring, surgery, or radiotherapy for localized prostate cancer. New Engl J Med 375(15):1415-1424. https://doi. org/10.1056/NEJMoa1606220

4. Hoffman KE, Penson DF, Zhao Z, Huang LC, Conwill R, Laviana AA, Joyce DD, Luckenbaugh AN, Goodman M, Hamilton AS, Wu XC, Paddock LE, Stroup A, Cooperberg MR, Hashibe M, O’Neil BB, Kaplan SH, Greenfield S, Koyama T, Barocas DA (2020) Patient-reported outcomes through 5 years for active surveillance, surgery, brachytherapy, or external beam radiation with or without androgen deprivation therapy for localized prostate cancer. JAMA 323(2):149-163. https://doi.org/10.1001/jama.2019.20675

5. Valerio M, Cerantola Y, Eggener SE, Lepor H, Polascik TJ, Villers A, Emberton M (2017) New and established technology in focal ablation of the prostate: a systematic review. Eur Urol 71(1):1734. https://doi.org/10.1016/j.eururo.2016.08.044

6. Connolly T, Reb J (2005) Regret in cancer-related decisions. Health Psychol 24(4S):S29-34. https://doi. org/10.1037/0278-6133.24.4.S29

7. Christie DR, Sharpley CF, Bitsika V (2015) Why do patients regret their prostate cancer treatment? A systematic review of regret after treatment for localized prostate cancer. Psychooncology 24(9):1002-1011. https://doi.org/10.1002/pon.3776

8. Hoffman RM, Lo M, Clark JA, Albertsen PC, Barry MJ, Goodman M, Penson DF, Stanford JL, Stroup AM, Hamilton AS (2017) Treatment decision regret among long-term survivors of localized prostate cancer: results from the prostate cancer outcomes study. J Clin Oncol Off J Am Soc Clin Oncol 35(20):2306-2314. https ://doi.org/10.1200/JCO.2016.70.6317

9. Clark JA, Inui TS, Silliman RA, Bokhour BG, Krasnow SH, Robinson RA, Spaulding M, Talcott JA (2003) Patients' perceptions of quality of life after treatment for early prostate cancer. J Clin Oncol Off J Am Soc Clin Oncol 21(20):3777-3784. https://doi. org/10.1200/JCO.2003.02.115

10. Clark JA, Wray NP, Ashton CM (2001) Living with treatment decisions: regrets and quality of life among men treated for metastatic prostate cancer. J Clin Oncol Off J Am Soc Clin Oncol 19(1):72-80. https://doi.org/10.1200/JCO.2001.19.1.72

11. von Hardenberg J, Westhoff N, Baumunk D, Hausmann D, Martini T, Marx A, Porubsky S, Schostak M, Michel MS, Ritter M (2018) Prostate cancer treatment by the latest focal HIFU device with MRI/TRUS-fusion control biopsies: a prospective evaluation. Urol Oncol 36(9):401. https://doi.org/10.1016/j.urolonc.2018.05.022 (e401-401 e409)

12. Wei JT, Dunn RL, Litwin MS, Sandler HM, Sanda MG (2000) Development and validation of the expanded prostate cancer index composite (EPIC) for comprehensive assessment of health-related quality of life in men with prostate cancer. Urology 56(6):899905. https://doi.org/10.1016/s0090-4295(00)00858-x

13. Skolarus TA, Dunn RL, Sanda MG, Chang P, Greenfield TK, Litwin MS, Wei JT, Consortium P (2015) Minimally important difference for the expanded prostate cancer index composite short form. Urology 85(1):101-105. https://doi.org/10.1016/j.urolo gy.2014.08.044
14. Charlson ME, Pompei P, Ales KL, MacKenzie CR (1987) A new method of classifying prognostic comorbidity in longitudinal studies: development and validation. J Chronic Dis 40(5):373-383. https://doi.org/10.1016/0021-9681(87)90171-8

15. Barrett AE (2003) Socioeconomic status and age identity: the role of dimensions of health in the subjective construction of age. J Gerontol B Psychol Sci Soc Sci 58(2):S101-109. https://doi. org/10.1093/geronb/58.2.s101

16. Rubin DC, Berntsen D (2006) People over forty feel $20 \%$ younger than their age: subjective age across the lifespan. Psychon Bull Rev 13(5):776-780. https://doi.org/10.3758/bf03193996

17. Ware J Jr, Kosinski M, Keller SD (1996) A 12-item short-form health survey: construction of scales and preliminary tests of reliability and validity. Med Care 34(3):220-233. https://doi. org/10.1097/00005650-199603000-00003

18. Lin GA, Aaronson DS, Knight SJ, Carroll PR, Dudley RA (2009) Patient decision aids for prostate cancer treatment: a systematic review of the literature. CA Cancer J Clin 59(6):379-390. https:// doi.org/10.3322/caac.20039

19. Watson V, McCartan N, Krucien N, Abu V, Ikenwilo D, Emberton M, Ahmed HU (2020) Evaluating the trade-offs men with localised prostate cancer make between the risks and benefits of treatments: the COMPARE study. J Urol. https://doi.org/10.1097/ JU.0000000000000754

20. van den Bos W, Muller BG, Ahmed H, Bangma CH, Barret E, Crouzet S, Eggener SE, Gill IS, Joniau S, Kovacs G, Pahernik S, de la Rosette JJ, Rouviere O, Salomon G, Ward JF, Scardino PT (2014) Focal therapy in prostate cancer: international multidisciplinary consensus on trial design. Eur Urol 65(6):1078-1083. https://doi.org/10.1016/j.eururo.2014.01.001

21. van Stam MA, Aaronson NK, Bosch J, Kieffer JM, van der Voort, van Zyp JRN, Tillier CN, Horenblas S, van der Poel HG (2020) Patient-reported outcomes following treatment of localised prostate cancer and their association with regret about treatment choices. Eur Urol Oncol 3(1):21-31. https://doi.org/10.1016/j. euo.2018.12.004

22. Brehaut JC, O'Connor AM, Wood TJ, Hack TF, Siminoff L, Gordon E, Feldman-Stewart D (2003) Validation of a decision regret scale. Med Decis Making 23(4):281-292. https://doi. org/10.1177/0272989X03256005

23. Mortezavi A, Krauter J, Gu A, Sonderer J, Bruhin J, Reeve KA, Held L, Donati OF, Rupp NJ, Moch H, Sulser T, Eberli D (2019) Extensive histological sampling following focal therapy of clinically significant prostate cancer with high intensity focused ultrasound. J Urol 202(4):717-724. https://doi.org/10.1097/JU.00000 00000000298

24. Tourinho-Barbosa RR, Sanchez-Salas R, Claros OR, ColluraMerlier S, Bakavicius A, Carneiro A, Stabile A, Moschini M, Cathala N, Tobias-Machado M, Cathelineau X (2020) Focal therapy for localized prostate cancer with either high intensity focused ultrasound or cryoablation: a single institution experience. J Urol 203(2):320-330. https://doi.org/10.1097/JU.0000000000000506

25. Bass EJ, Ahmed HU (2016) Focal therapy in prostate cancer: a review of seven common controversies. Cancer Treat Rev 51:2734. https://doi.org/10.1016/j.ctrv.2016.07.004

26. Marra G, Valerio M, Emberton M, Heidenreich A, Crook JM, Bossi A, Pisters LL (2019) Salvage local treatments after focal therapy for prostate cancer. Eur Urol Oncol 2(5):526-538. https ://doi.org/10.1016/j.euo.2019.03.008

27. Kinsella J, Acher P, Ashfield A, Chatterton K, Dasgupta P, Cahill D, Popert R, O'Brien T (2012) Demonstration of erectile management techniques to men scheduled for radical prostatectomy reduces long-term regret: a comparative cohort study. BJU International 109(2):254-258. https://doi.org/10.1111/j.1464410X.2011.10237.X 
28. Lin YH (2011) Treatment decision regret and related factors following radical prostatectomy. Cancer Nurs 34(5):417-422. https ://doi.org/10.1097/NCC.0b013e318206b22b
Publisher's Note Springer Nature remains neutral with regard to jurisdictional claims in published maps and institutional affiliations. 